\title{
Waiting Too Long: The Contribution of Delayed Surgical Access to Pediatric Disease Burden in Somaliland
}

\author{
Emily R. Smith ${ }^{1,2} \cdot$ Tessa L. Concepcion ${ }^{1} \cdot$ Mark Shrime $^{3,4} \cdot$ Kelli Niemeier $^{2}$. \\ Mubarak Mohamed $^{5} \cdot$ Shugri Dahir $^{5} \cdot$ Edna Adan Ismail $^{5} \cdot$ Dan Poenaru $^{6}$. \\ Henry E. Rice ${ }^{1}$ on behalf of the Global Initiative for Children's Surgery
}

Published online: 25 October 2019

(C) Société Internationale de Chirurgie 2019

\begin{abstract}
Background Delayed access to surgical care for congenital conditions in low- and middle-income countries is associated with increased risk of death and life-long disabilities, although the actual burden of delayed access to care is unknown. Our goal was to quantify the burden of disease related to delays to surgical care for children with congenital surgical conditions in Somaliland.

Methods We collected data from medical records on all children $(n=280)$ receiving surgery for a proxy set of congenital conditions over a 12-month time period across all 15 surgically equipped hospitals in Somaliland. We defined delay to surgical care for each condition as the difference between the ideal and the actual ages at the time of surgery. Disability-adjusted life years (DALYs) attributable to these delays were calculated and compared by the type of condition, travel distance to care, and demographic characteristics.

Results We found long delays in surgical care for these 280 children with congenital conditions, translating to a total of 2970 attributable delayed DALYs, or 8.4 avertable delayed DALYs per child, with the greatest burden among children with neurosurgical and anorectal conditions. Over half of the families seeking surgical care had to travel over $2 \mathrm{~h}$ to a surgically equipped hospital in the capital city of Hargeisa.

Conclusions Children with congenital conditions in Somaliland experience substantial delays to surgical care and travel long distances to obtain care. Estimating the burden of delayed surgical care with avertable delayed DALYs offers a powerful tool for estimating the costs and benefits of interventions to improve the quality of surgical care.
\end{abstract}

Emily R. Smith

Emily_r_smith@baylor.edu

1 Duke Global Health Institute, Duke University, Durham, NC, USA

2 Department of Public Health, Robbins College of Health and Human Sciences, Baylor University, MMGYM Room 218, One Bear Place \#97313, Waco, TX 76798-7313, USA

3 Center for Global Surgery Evaluation, Massachusetts Eye and Ear Infirmary, Boston, MA, USA

4 Program in Global Surgery and Social Change, Harvard Medical School, Boston, MA, USA

5 Edna Adan University Hospital, Hargeisa, Somaliland

6 McGill University, Montreal, QC, Canada

\section{Introduction}

Timely surgical care is essential for the provision of highquality health care, and delays in care may lead to needless suffering as well as poor outcomes from surgical procedures. Within low- and middle-income countries (LMICs), the need for surgical care among children is great, as more than $50 \%$ of the population are children, many of whom have significant surgical needs [1-3]. Congenital conditions affect an estimated 150 million children around the world, with $92 \%$ of the congenital conditions occurring in LMICs [4, 5]. Moreover, an estimated $17-43 \%$ of infant mortality is attributed to congenital anomalies. [6] 
The preferred metric for measuring the global burden of disease is the disability-adjusted life year (DALY), which estimates the gap between current and ideal health statuses, and accounts for both the mortality and morbidity of a health state [7]. The Global Burden of Disease (GBD) study has been indispensable in informing policy and resource allocation by providing detailed measures of disease burden across populations using the DALY metric [7]. In the case of surgical conditions, DALYs should reflect both the patient statuses before and after surgical treatment, as well as account for the timeliness of receiving care and hence the burden of waiting [8, 9]. Burden of disease assessment can distinguish between met need measured in averted DALYs following provision of surgical care, unmet need measured in avertable DALYs if surgical care is possible but is not provided, and unavertable need resulting from unavoidable health consequences regardless of any surgical intervention [9]. Finally, delayed DALYs can quantify the "lost" suffering of patients who had lived for years with their disabling surgical condition before surgical care was eventually provided [10].

Targeted interventions to reduce the burden of unmet surgical care can inform strategic allocation of health resources. However, few studies have quantified the contribution of delayed access to care to the unmet surgical burden of disease, particularly for surgical conditions in children. In this study, we measured delays to surgical care for children with congenital surgical conditions in LMICs, specifically quantifying the met, unmet, and delayed burden of surgical conditions using the DALY metric. This study is an extension of our previous work exploring surgical care for children in Somaliland, in which we have demonstrated a high prevalence of surgical conditions in children across the country [11].

\section{Materials and methods}

We performed a nationwide analysis using secondary data collected from medical records across all 15 surgically equipped hospitals in Somaliland. We collected data on all children receiving surgery for a proxy set of congenital conditions over a 12-month time period. The ideal age of surgery for each condition was derived using current clinical practice guidelines across both high-income countries and LMICs for all conditions. We defined delays to surgical care for each condition as the difference between the ideal and the actual ages at the time of surgery. DALYs attributable to the delays were then calculated as detailed below. Delays in care were compared by surgical specialty, distance to definitive care, and demographic characteristics.

\section{Setting}

With a gross domestic product per capita of \$347 (PPP), Somaliland is the fourth poorest country in the world and is classified as a low-income country by World Health Income group [12]. Pediatric health metrics in Somaliland are some of the lowest globally, with infant and under-5 mortality rates over double the sub-Saharan African average [13].

\section{Data collection}

We collected data from all hospitals in Somaliland having surgical capacity for children, with hospitals identified by Somaliland medical officials and local medical leadership, as summarized in the parent study [11]. In brief, all hospital surgical records for cases at 15 hospitals in Somaliland between August 2016 and July 2017 were reviewed. We chose to include only congenital conditions, since the date of onset of the condition is uniformly known as the date of birth, facilitating the calculation of attributable DALYs. We collected data on patient age, gender, village and region of residence, surgical procedure performed, date of surgery, and functional outcome (if available).

\section{Proxy set of congenital conditions}

We identified all children with congenital conditions between August 2016 and July 2017 at the 15 selected hospitals $(n=285)$. Of the 285 children, 5 had an unspecified congenital condition indicated as a birth defect and were eliminated from the final study sample, resulting in 280 children (Table 1). We classified these children into specialty categories, including neurosurgery (hydrocephalus, spina bifida, and encephalocele), plastic surgery (cleft lip and/or cleft palate), orthopedic surgery (clubfoot), general surgery (anorectal malformations and inguinal hernia), and urology (hypospadias).

\section{Travel distances}

Patients' self-reported villages of residence were located through Google Maps and confirmed with local collaborators for accuracy. In cases where villages could not be located on Google Maps, the location was identified through consensus by Somaliland hospital staff, Ministry of Health officials, and professional drivers, and then given approximate GPS coordinates. To estimate travel time to surgical care, we chose to measure travel time (in hours) for each child to the capital city of Hargeisa, since $86 \%$ of children with congenital anomalies in our study received care in Hargeisa. Travel time was defined as the time it takes in hours for a driver with a vehicle to travel to 
Table 1 Number of procedures, by gender and residence region

\begin{tabular}{|c|c|c|c|c|c|c|c|c|c|}
\hline & \multirow[b]{2}{*}{$\begin{array}{l}\text { Total } \\
(n=280) \\
n(\%)\end{array}$} & \multicolumn{2}{|l|}{ Gender } & \multicolumn{2}{|c|}{$\begin{array}{l}\text { Region where surgery was } \\
\text { received }\end{array}$} & \multicolumn{4}{|c|}{ Travel distance to receive surgery in Hargeisa } \\
\hline & & $\begin{array}{l}\text { Male } \\
(n=168) \\
n(\%)\end{array}$ & $\begin{array}{l}\text { Female } \\
(n=112) \\
n(\%)\end{array}$ & $\begin{array}{l}\text { Maroodi } \\
\text { Jeex } \\
(n=249) \\
n(\%)\end{array}$ & $\begin{array}{l}\text { Other } \\
\text { regions } \\
(n=31) \\
n(\%)\end{array}$ & $\begin{array}{l}\text { Within } 2 \mathrm{~h} \\
(n=139) \\
n(\%)\end{array}$ & $\begin{array}{l}2.1-6 \mathrm{~h} \\
(n=61) \\
n(\%)\end{array}$ & $\begin{array}{l}6.1-10 \mathrm{~h} \\
(n=19) \\
n(\%)\end{array}$ & $\begin{array}{l}\text { Greater than } \\
10 \mathrm{~h}(n=61) \\
n(\%)\end{array}$ \\
\hline Neurosurgery & $141(50.4)$ & $74(44.0)$ & $67(59.8)$ & $135(54.2)$ & $6(19.4)$ & $46(33.1)$ & $36(59.0)$ & $14(73.7)$ & $45(73.8)$ \\
\hline Hydrocephalus & $95(67.3)$ & $56(75.7)$ & $39(58.2)$ & $93(68.9)$ & $2(33.3)$ & $23(50.0)$ & $29(80.6)$ & $8(57.1)$ & $35(77.8)$ \\
\hline Spina Bifida & $39(27.8)$ & $18(24.3)$ & $21(31.3)$ & $35(25.9)$ & $4(66.7)$ & $19(41.3)$ & $5(13.9)$ & $5(35.7)$ & $10(22.2)$ \\
\hline Encephalocele & $7(4.9)$ & $0(0.0)$ & $7(10.5)$ & $7(5.2)$ & $0(0.0)$ & $4(8.7)$ & $2(5.5)$ & $1(7.1)$ & $0(0.0)$ \\
\hline Plastic Surgery & $81(29.3)$ & $54(32.1)$ & $27(24.1)$ & $63(25.3)$ & $18(58.1)$ & $62(44.6)$ & $12(19.7)$ & $2(10.5)$ & $5(8.2)$ \\
\hline Cleft Lip & $49(60.5)$ & $33(61.1)$ & $16(59.3)$ & $41(65.1)$ & $8(44.4)$ & $36(58.1)$ & $9(75.0)$ & $0(0.0)$ & $4(80.0)$ \\
\hline $\begin{array}{l}\text { Cleft Palate } \\
\text { (with/ } \\
\text { without CL) }\end{array}$ & $32(39.5)$ & $21(38.9)$ & $11(40.7)$ & $22(34.9)$ & $10(55.6)$ & $26(41.9)$ & $3(25.0)$ & $2(100.0$ & $1(20.0)$ \\
\hline Orthopedics & $24(8.6)$ & $14(8.3)$ & $10(8.9)$ & $24(9.6)$ & $0(0.0)$ & $10(7.2)$ & $5(8.2)$ & $2(10.5)$ & 7 (11.5) \\
\hline Clubfoot & $24(100.0)$ & $14(100.0)$ & $10(100.0)$ & $24(100.0)$ & $0(0.0)$ & $10(100.0)$ & $5(100.0)$ & $2(100.0)$ & $7(100.0)$ \\
\hline General Surgery & $23(8.2)$ & $15(8.9)$ & $8(7.1)$ & $18(7.2)$ & $5(16.1)$ & $12(8.6)$ & 7 (11.5) & $1(5.3)$ & $3(4.9)$ \\
\hline $\mathrm{ARM}$ & $13(56.5)$ & $6(60.0)$ & 7 (87.5) & $13(72.2)$ & $0(0.0)$ & $8(66.7)$ & $2(28.6)$ & $1(100.0)$ & $2(66.7)$ \\
\hline Inguinal Hernia & $10(43.5)$ & $9(40.0)$ & $1(12.5)$ & $5(27.8)$ & $5(100.0)$ & $4(33.3)$ & $5(71.4)$ & $0(0.0)$ & $1(33.3)$ \\
\hline Urology & $11(3.9)$ & $11(6.6)$ & $0(0.0)$ & $9(3.6)$ & $2(6.5)$ & $9(6.5)$ & $1(1.6)$ & $0(0.0)$ & $1(1.6)$ \\
\hline Hypospadias & $11(100.0)$ & $11(100.0)$ & $0(0.0)$ & $9(100.0)$ & $2(100.0)$ & $9(100.0)$ & $1(100.0)$ & $0(0.0)$ & $1(100.0)$ \\
\hline
\end{tabular}

$A R M$ anorectal malformation, $C L$ cleft lip

Hargeisa given current road conditions and was defined for each child through consensus by Somaliland hospital staff, Ministry of Health officials, and professional drivers. Travel time was stratified as $0-2 \mathrm{~h}, 2.1-6 \mathrm{~h}, 6.1-10 \mathrm{~h}$, or more than $10 \mathrm{~h}$. In cases where the village of residence was outside of Somaliland (i.e., Somalia or Ethiopia), travel times were considered $24 \mathrm{~h}$ due to the large number of variables which can affect travel.

\section{DALY calculations}

The DALY metric measures overall disease burden by incorporating years of life lost to poor health, disability, or early death [14]. We calculated DALYs attributable to delays in surgical care (delayed DALYs) as the burden resulting from the difference between the optimal and actual dates of surgery (Fig. 1). The optimal age of surgery, for each condition, was incorporated in the DALY metric according to established recommended ages for intervention, while the actual age of surgery was collected from the surgical record review [15-22]. The disability weights (DW) for each condition both before and after surgical interventions were obtained from published values [23] or, for conditions without available DWs, estimated by combining expected disabilities associated with the condition based on Salomon's classification [24, 25]. Conditional

$$
\begin{aligned}
& \begin{array}{l}
\text { Fig. 1 Calculation of DALYs } \\
\text { attributable to delayed care }
\end{array} \\
& D A L Y_{a}=\left(\sum_{t=0}^{D O S_{a c t}} d w_{u}+\sum_{t=D O S_{a c t}}^{L E_{D O S}} d w_{t}\right)-\left(\sum_{t=0}^{D O S_{o p t}} d w_{u}+\sum_{t=D O S_{\text {opt }}}^{L E_{D O S}} d w_{t}\right) \\
& \text { With discounting } \\
& D A L Y_{a}=\left(\sum_{t=0}^{D O S_{a c t}} \frac{d w_{u}}{(1+r)^{t}}+\sum_{t=D O S_{a c t}}^{L E_{D O S}} \frac{d w_{t}}{(1+r)^{t}}\right)-\left(\sum_{t=0}^{D O S_{o p t}} \frac{d w_{u}}{(1+r)^{t}}+\sum_{t=D O S_{o p t}}^{L E_{D O S}} \frac{d w_{t}}{(1+r)^{t}}\right) \\
& \text { where } r=\text { discount rate, DOS } S_{\text {opt }} \text { and DOS } S_{a c t} \text { are the optimal and actual dates } \\
& \text { of surgery, and } L E_{D O S} \text { is the conditional life expectancy given that the patient } \\
& \text { has survived to the date of their surgery (ie, not LE at birth). }
\end{aligned}
$$


country-specific life expectancies in 2016 for males and females were calculated from the age of the child at the date of their surgery. The life expectancy at birth was used for children less than 1 year (53.7 years for males, 57.3 years for males). After 1 year of age, the following conditional life expectancies were used: 57.9 years for males and 61.1 years for females between the ages of 1 to 4 years; 57.2 years for males, 60.6 years for females between 5 and 9 years; 53.3 years for males and 56.7 years for females between 10 and 14 years; and 48.7 years for males and 52.1 years for females older than 15 years. A $3 \%$ discount rate was used for future DALYs [26].

\section{Statistical analysis}

Demographic characteristics of the children, including gender, region where the surgery was received, and travel distance to the capital city of Hargeisa were compared between surgical specialties and within each specialty by specific condition. The delayed DALYs were compared by surgical specialty, condition, gender, age, region where surgery was received, and travel time to Hargeisa using the Wilcoxon Chi-squared test statistic between median values for each group.

\section{Ethical considerations}

Institutional review board (IRB) approval was granted from Duke University. Since Somaliland does not have a national IRB, a letter of approval was granted from the Somaliland Ministry of Health. Participants in the community survey offered verbal consent for study participation. A parent or guardian provided consent for all children younger than 15 years old, and children between the ages of 12 and 15 provided assent. For the majority of children enrolled, parents answered all questions in the survey. Patients or public members were not involved in the development, design, or recruitment of the study. Results will be disseminated to the patients and relevant communities through the collaboration with the in-country partners at the Edna Adan University Hospital.

\section{Results}

We found long delays in presentation to surgical care for children with congenital conditions, translating to a total of 2362 DALYs attributable to delays in care for the 280 children - or an average of 8.4 avertable delayed DALYs per child, a value similar to other public health interventions in resource-limited settings. The greatest delayed burden was due to children with anorectal malformations and hypospadias, which had nearly three times the average number of delayed DALYs for 280 children.

Over a 12-month period, 280 children received a surgical procedure for congenital conditions. Most children (60\%) were male, and 249 (89\%) were from the urban region of Maroodi Jeex (Table 1). Stratified by surgical specialty, $141(50 \%)$ received neurosurgical procedures, 81 (29\%) plastic surgical procedures, 9\% orthopedic procedures, and the remaining children underwent general surgical or urologic procedures. Among the 280 children, 139 travelled less than $2 \mathrm{~h}, 612.1$ to $6 \mathrm{~h}, 19$ children 6.1 to $10 \mathrm{~h}$, and 61 children more than $10 \mathrm{~h}$ (Fig. 2).

The median age at surgery ranged from less than 1 month (interquartile range IQR: $0.69,7.0$ ) for children with encephaloceles to 120 months (IQR: 60.0, 132.0) for children with hypospadias, resulting in median delays ranging from 1 month (IQR: $0.69,7.0$ ) for encephaloceles to 108 months (IQR: 48.0, 120.0) for hypospadias (Table 2). A total of 2362.2 DALYs were associated with delayed presentation to surgical care. Avertable DALYs associated with delayed presentation to surgical care ranged from less than 290 for urologic and orthopedic conditions to over 700 for neurosurgical conditions.

Delayed avertable DALYs were higher among males compared to females (1538.0 versus 823.3 DALYs, respectively) (Fig. 3). When stratified by age, older children had more delayed avertable DALYs than children younger than 4 years of age. Delayed DALYs equaled 2223.0 in the Maroodi Jeex region, compared to 139.2 in the other regions. Children who lived within $2 \mathrm{~h}$ of Hargeisa had the highest number of delayed DALYs, followed by children who lived over $10 \mathrm{~h}$ away.

\section{Discussion}

In LMICs, timely receipt of surgical care for children with congenital conditions is critical, as congenital conditions are associated with life-long disabilities or mortality if not promptly treated [6, 27-29]. We found substantial delays to surgical care for children with congenital conditions in Somaliland. Assessing the burden of delayed unmet surgical care provides an opportunity to quantify the impact of delays on overall disease burden and gives us a powerful tool to estimate the costs and benefits of interventions to reduce delays in care.

The DALYs metric is the most common health metric used in global disease burden computations, cost-effectiveness studies, and analyses of allocation of resources [30]. Although estimating the cost-effectiveness and financial impact of pediatric surgical conditions is challenging in LMICs [31, 32], it is essential to quantify the impact of delayed care to understand the economic impact 


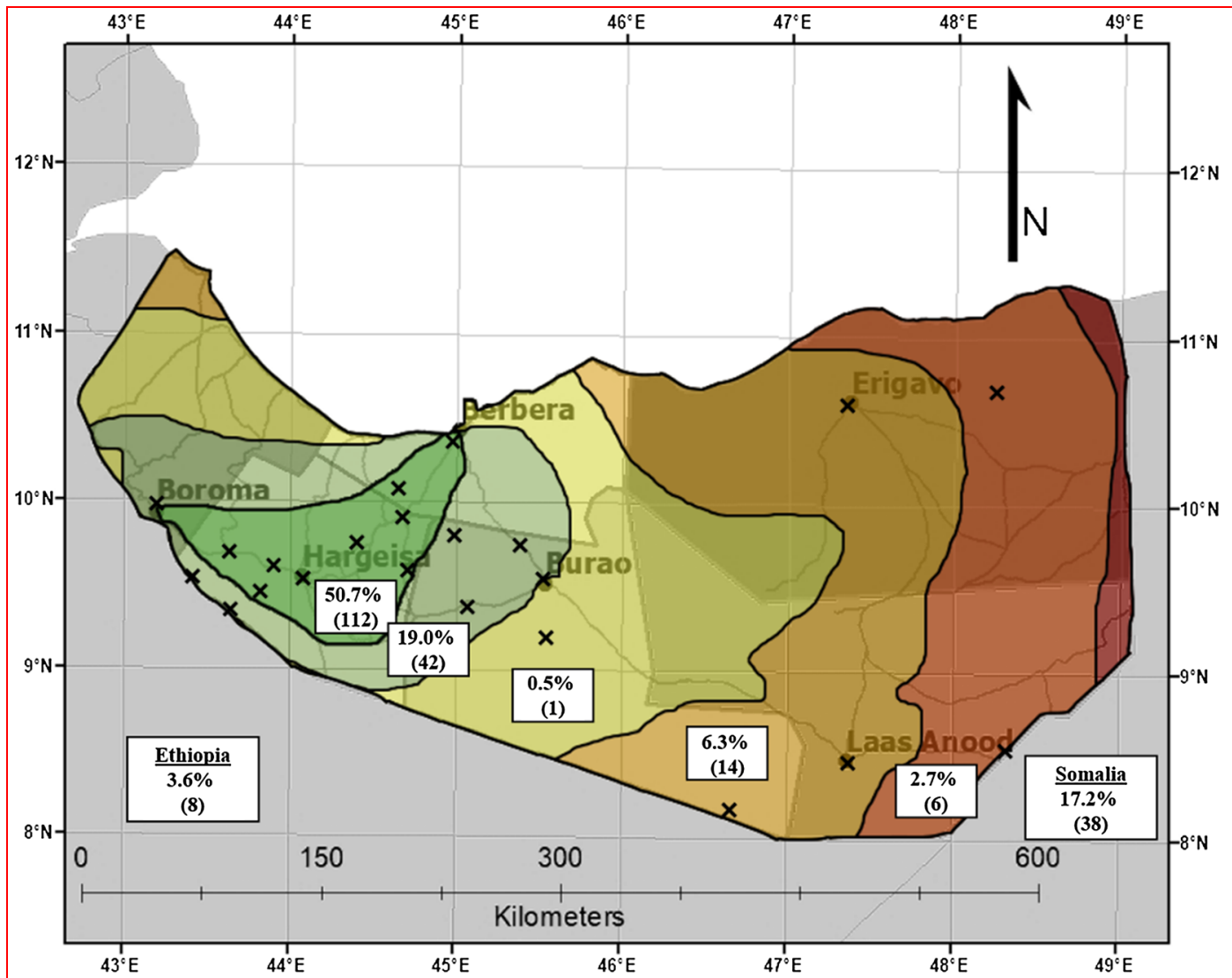

\begin{tabular}{|l|}
\hline Within 2 hours \\
\hline Within 4 hours \\
\hline Within 6 hours \\
\hline Within 8 hours \\
\hline Within 10 hours \\
\hline
\end{tabular}

$x$

Child town of origin

*includes children seen at hospitals in Hargeisa who identified their village of residence

Fig. 2 Travel distances to receive surgical care for congenital conditions at hospitals in Hargeisa $(n=221) *$. *includes children seen at hospitals in Hargeisa who identified their village of residence

of these conditions. Delays in the provision of surgical care in children result not only in needless suffering, but can also increase the economic impact on a child and community. Although congenital conditions are not always lifethreatening, severe disability can occur if not treated promptly. For example, untreated or delays in treatment for cleft lip and/or palate can result in breastfeeding and eating hardships, resulting in malnutrition or stunting, and stigma or social discrimination $[33,34]$. Delayed care to definitive treatment of anorectal malformations can result in substantial morbidity, stigmatization, and barriers to attending school [35]. In addition, delayed presentation to care increases the likelihood of having a comorbidity of chronic constipation, anemia, malnutrition, and fecal impaction, thereby influencing the efficacy of surgical intervention if sought.

The traditional use of the DALY metric does not allow for understanding of how delays in care in impact burden of disease assessment, nor does it account for variable residual disabilities postoperatively. Recent editions of the GBD study have provided postoperative (residual) disability weight values for a small group of pediatric conditions [24]. However, these values are based on the assumption that treatment was provided at the appropriate time and to a standard of surgical care, not for delayed care which may be associated with greater disease severity and increased potential for postoperative surgical complications [23]. In our study, we used the approach of incorporating delays in care directly into the DALY metric by adjusting for the age at presentation, thereby accounting for the "lost" burden suffered by children while waiting for their surgical care [36]. Although this calculation still does not account for the potentially higher residual disability after surgery when surgical care is provided at a more advanced age, incorporating delayed DALYs results in more accurate burden of disease and economic impact estimates [24, 37-40].

The delayed DALYs related to surgical procedures for children (mean of 8.4 averted DALYs/child) are comparable to other public health interventions. For example, antiretroviral therapy to prevent mother-to-child transmission of HIV averts 8.6 DALYs compared to no treatment 
Table 2 Recommended age of surgery, disability weights, mean delay to surgery, and delayed averted burden, by condition

\begin{tabular}{|c|c|c|c|c|c|c|c|}
\hline & $\begin{array}{l}\text { Recommended } \\
\text { age of surgery }\end{array}$ & $\begin{array}{l}\text { Disability } \\
\text { weight } \\
\text { (untreated) }\end{array}$ & $\begin{array}{l}\text { Disability } \\
\text { weight } \\
\text { (treated) }\end{array}$ & $\begin{array}{l}\text { Median age at } \\
\text { presentation } \\
\text { (months, IQR) }\end{array}$ & $\begin{array}{l}\text { Median delay to } \\
\text { surgery (months, } \\
\text { IQR) }\end{array}$ & $\begin{array}{l}\text { Total } \\
\text { averted } \\
\text { DALYs }\end{array}$ & $\begin{array}{l}\text { Mean averted } \\
\text { DALYs per } \\
\text { child }\end{array}$ \\
\hline Neurosurgery & & & & $5.0(1.5,8.0)$ & $4.0(1.0,7.0)$ & 702.1 & 4.9 \\
\hline Hydrocephalus & 1 month [15] & $0.74[48]$ & $0.30[49]$ & $6.0(2.0,9.0)$ & $5.0(1.0,8.0)$ & 613.6 & 6.5 \\
\hline Spina Bifida & $\begin{array}{c}48 \mathrm{~h} \text { of life } \\
{[16]}\end{array}$ & $0.605[48]$ & $0.221[49]$ & $2.0(0.66,5.0)$ & $1.9(0.59,4.9)$ & 79.1 & 2.1 \\
\hline Encephalocele & At birth [17] & $0.60[50]$ & $0.221[49]$ & $1.0(0.69,7.0)$ & $1.0(0.69,7.0)$ & 9.5 & 1.4 \\
\hline Plastic Surgery & & & & & $27.0(4.5,67.5)$ & 634.78 & 7.8 \\
\hline Cleft Palate & $\begin{array}{l}6-12 \text { months } \\
{[18]}\end{array}$ & $0.231[49]$ & $0.013[49]$ & $60.0(19.5,66.0)$ & $51.0(10.5,57.0)$ & 284.7 & 5.8 \\
\hline Cleft Lip & $\begin{array}{c}3-6 \text { months } \\
{[18]}\end{array}$ & $0.122[51]$ & $0.013[49]$ & $24.0(9.0,72.0)$ & $19.5(4.5,67.5)$ & 350.1 & 10.9 \\
\hline Orthopedic & & & & $54.0(21.0,120.0)$ & $47.0(14.0,113.0)$ & 236.9 & 9.8 \\
\hline Clubfoot & 7 months [19] & $0.20[50]$ & 0.013 [49] & $54.0(21.0,120.0)$ & $47.0(14.0,113.0)$ & 236.9 & 9.8 \\
\hline General Surgery & & & & $42.0(3.0,72.0)$ & $35.9(0.0,59.0)$ & 507.2 & 22.1 \\
\hline ARM & $\begin{array}{l}\text { Within } 3 \text { days } \\
\text { [20] }\end{array}$ & $0.85[50]$ & $0.123[49]$ & $36.0(0.0,60.0)$ & $35.9(0.0,59.9)$ & 365.1 & 28.1 \\
\hline $\begin{array}{l}\text { Inguinal } \\
\text { hernia }\end{array}$ & 3 years [21] & $0.50[52]$ & $0.00[49]$ & $57.0(24.0,72.0)$ & $21.0(0.0,36.0)$ & 142.1 & 14.2 \\
\hline Urology & & & & $120.0(60.0,132.0)$ & $108.0(48.0,120.0)$ & 281.2 & 25.6 \\
\hline \multirow[t]{2}{*}{ Hypospadias } & $\begin{array}{l}6-18 \text { months } \\
{[22]}\end{array}$ & $0.31[48]$ & $0.013[49]$ & $120.0(60.0,132.0)$ & $108.0(48.0,120.0)$ & 281.2 & 25.6 \\
\hline & & & & & TOTAL & 2362.2 & 8.4 \\
\hline
\end{tabular}

ARM anorectal malformation; IQR interquartile range; SD standard deviation

Mean ages used include: 9 months—cleft palate with or without cleft lip; 4.5 months—cleft lip; 12 months—hypospadias

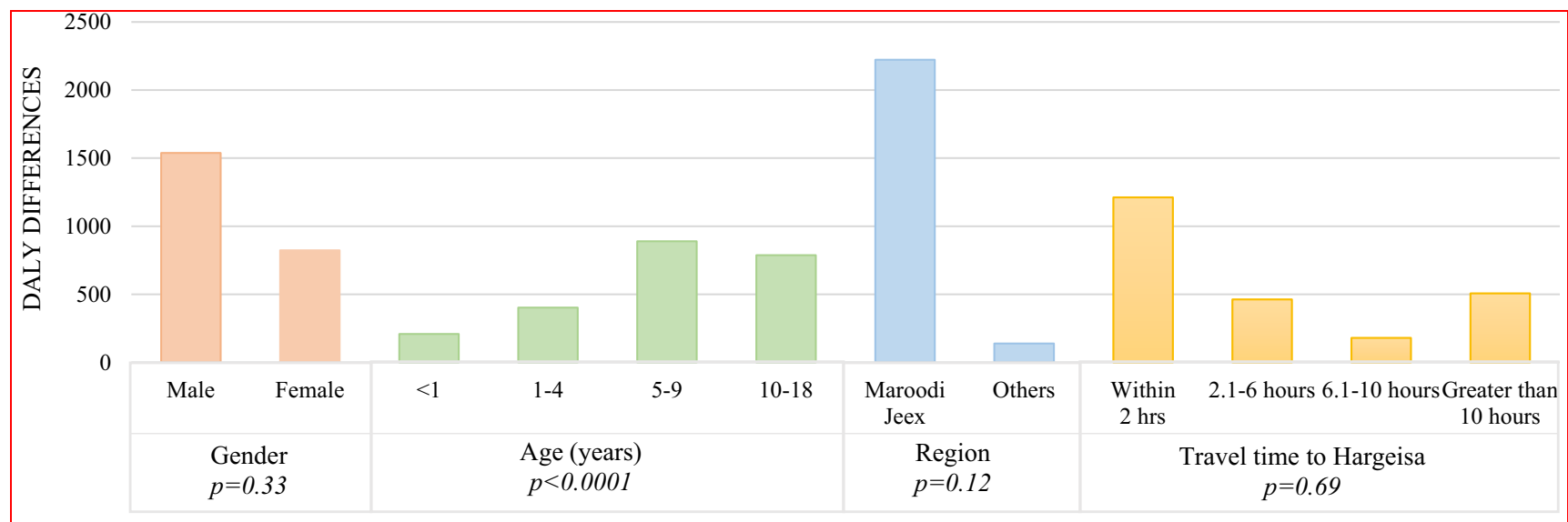

Fig. 3 Delayed DALY differences by gender, age, region, and travel time

[41]. Investment in surgical care is a cost-effective public health measure [42]. We found a similar large number of delayed averted DALYs for patients with hypospadias and anorectal malformations [43].

The provision of high-quality surgical care is multi-dimensional and requires prompt care as well as adequately trained workforce, supplies, and other resources [44-46].
Our data provide evidence of the large impact of delays in surgical care among children with congenital anomalies in low-income settings. The inability to receive surgical care depends on many barriers, including patient, institutional, and structural factors [2, 47-52]. At a patient level, the delay in receiving surgical care often occurs because of financial restrictions or travel barriers if a health facility is 
too far away. In Somaliland, $29 \%$ of people live in urban areas such as Maroodi Jeex, and $38 \%$ of those living in rural areas are classified as living in poverty [53]. In addition, families with a child with a surgical need are more likely to become impoverished and remain in poverty due to the expenses around the procedure and other nonmedical costs [54]. Interestingly, the highest number of delayed DALYs occurred among children from that same area, indicating that even families living close to the country's highest level hospitals experience long delays in care.

Our study has several limitations: First, although the surgical logbooks contained information on the children's age, procedure, and residence location, we were not able to assess elements which could influence delays in care, such as manpower or infrastructure limitations, or associated comorbidities. Second, our calculations for delays in care rely on published recommended ages at which children in high-income countries (HIC) typically undergo surgical care. Although these ages have been used in similar analyses of surgical care in LMICs [55], such recommendations may not be transposable to the context of care in Somaliland-where, for instance, safe pediatric anesthesia considerations may delay the ideal surgical time. Third, the institution-based design of our study would exclude children with similar conditions who never reached a hospital, suggesting a potential survivor bias. Thus, the DALY estimates may underestimate the true burden of disease for congenital conditions. Future studies would ideally include community-derived data in order to account for the hidden burden of children who die before reaching hospital care [56].

In summary, our study demonstrates a significant and quantifiable burden of delayed surgical care for children with congenital conditions in Somaliland. Moving forward, quantifying further the impact of delays in care may be helpful for accurately assessing the burden of conditions requiring surgery in LMICs [57]. Further research on the causes of delays in care may help identify specific geographic regions or populations to target for health care expansion and inform the future configuration of services. Our findings further support the growing body of evidence that scaling up pediatric surgery in LMICs can markedly improve the quality and outcomes of health care of children.

Acknowledgements We want to thank the Global Initiative for Children's Surgery (GICS) for its support of this work. GICS (www. globalchildrenssurgery.org) is a network of children's surgical and anesthesia providers from low-, middle-, and high-income countries collaborating for the purpose of improving the quality of surgical care for children globally.
Funding The funding was provided by the Duke Global Health Institute, Duke University, and by the Robbins College of Health and Human Sciences, Baylor University.

\section{References}

1. Abdelgadir J, Punchak M, Smith ER et al (2018) Pediatric traumatic brain injury at Mbarara Regional Referral Hospital, Uganda. J Clin Neurosci Off J Neurosurg Soc of Australas 47:79-83

2. Butler EK, Tran TM, Fuller AT et al (2016) Quantifying the pediatric surgical need in Uganda: results of a nationwide crosssectional, household survey. Pediatr Surg Int 32(11):1075-1085

3. Butler EK, Tran TM, Nagarajan N et al (2017) Epidemiology of pediatric surgical needs in low-income countries. PLoS ONE 12(3): 0170968

4. Bhide P, Gund P, Kar A (2016) Prevalence of congenital anomalies in an Indian maternal cohort: healthcare, prevention, and surveillance implications. PLoS ONE 11(11):e0166408

5. Vos T, Kyu HH, Pinho C et al (2016) Global and national burden of diseases and injuries among children and adolescents between 1990 and 2013 findings from the global burden of disease 2013 study. JAMA Pediatr 170(3):267-287

6. Wang H, Bhutta ZA, Coates MM, Coggeshall M, Dandona L, Diallo K, Franca EB, Fraser M, Fullman N, Gething PW, Hay SI (2016) Global, regional, national, and selected subnational levels of stillbirths, neonatal, infant, and under-5 mortality, 1980-2015: a systematic analysis for the Global Burden of Disease Study 2015. Lancet 388(10053):1725-1774

7. LA Murray CJL (1996) The Global Burden of Disease: a comprehensive assessment of mortality and disability from diseases, injuries, and risk factors in 1990 and projected to 2020. Harvard University Press, Cambridge

8. Bickler S, Ozgediz D, Gosselin R et al (2010) Key concepts for estimating the burden of surgical conditions and the unmet need for surgical care. World J Surg 34(3):374-380. https://doi.org/10. 1007/s00268-009-0261-6

9. Poenaru D (2016) The burden of pediatric surgical disease in lowresource settings: discovering it, measuring it, and addressing it. J Pediatr Surg 51(2):216-220

10. Poenaru D, Ozgediz D, Gosselin RA (2014) Burden, need, or backlog: a call for improved metrics for the global burden of surgical disease. Int J Surg 12(5):483-486

11. Concepcion T, Mohamed M, Dahir S et al (2019) Prevalence of pediatric surgical conditions across Somaliland. JAMA Netw Open 2(1):e186857

12. Bank W(2018) New World Bank GDP and Poverty Estimates for Somaliland. http://www.worldbank.org/en/news/press-release/ 2014/01/29/new-world-bank-gdp-and-poverty-estimates-forsomaliland. Accessed 1 July 2018

13. Global Health Repository data (2018) World Health Organization. http://www.who.int/gho/database/en/. Accessed 2 April 2018

14. Murray CJ (1994) Quantifying the burden of disease: the technical basis for disability-adjusted life years. Bull World Health Organ 72(3):429-445

15. Warf BC, East African Neurosurgical Research C (2010) Pediatric hydrocephalus in East Africa: prevalence, causes, treatments, and strategies for the future. World Neurosurg 73(4):296-300

16. Surgeons AAoN (2018) Spina Bifida. 2018; https://www.aans.org/ Patients/Neurosurgical-Conditions-and-Treatments/Spina-Bifida 
17. Control CfD (2018) Birth defects: Facts about Encephalocele 2017; https://www.cdc.gov/ncbddd/birthdefects/encephalocele. html

18. Service NH. Treatment (2018) Cleft lip and palate. 2016; https:// www.nhs.uk/conditions/cleft-lip-and-palate/treatment/

19. Templeton PA, Flowers MJ, Latz KH, Stephens D, Cole WG, Wright JG (2006) Factors predicting the outcome of primary clubfoot surgery. Can J Surg 49(2):123-127

20. Ishitani MB (2018) Anorectal malformation. 2016; http://www. eapsa.org/parents/conditions/a-e/anorectal-malformation/

21. Chan YY, Durbin-Johnson B, Kurzrock EA (2016) Pediatric inguinal and scrotal surgery-practice patterns in US academic centers. J Pediatr Surg 51(11):1786-1790

22. Clearinghouse EAoUatNG (2018) Guidelines and measures. 2009; www.guideline.gov/content.aspx?id=12594

23. Smith ER, Concepcion T, Lim S et al (2018) Disability weights for pediatric surgical procedures: a systematic review and analysis. World J Surg 42:3021-3034. https://doi.org/10.1007/ s00268-018-4537-6

24. Salomon JA, Haagsma JA, Davis A et al (2015) Disability weights for the Global Burden of Disease 2013 study. Lancet Global Health 3(11):e712-723

25. Shrime MG, Alkire BC, Grimes C, Chao TE, Poenaru D, Verguet S (2017) Cost-effectiveness in global surgery: pearls, pitfalls, and a checklist. World J Surg 41:1401-1413. https://doi.org/10.1007/ s00268-017-3875-0

26. Murray CJ, Ezzati M, Flaxman AD et al (2012) GBD 2010: design, definitions, and metrics. Lancet 380(9859):2063-2066

27. Davé DR, Nagarjan N, Canner JK, Kushner AL, Stewart BT, Group SR (2018) Rethinking burns for low \& middle-income countries: differing patterns of burn epidemiology, care seeking behavior, and outcomes across four countries. Burns 44:1228-1234

28. Abdelgadir J, Smith ER, Punchak M et al (2017) Epidemiology and characteristics of neurosurgical conditions at Mbarara regional referral hospital. World Neurosurg 102:526-532

29. Abdelgadir J, Smith E, Punchak M et al (2017) Outcomes and predictors of mortality in neurosurgery patients at Mbarara regional referral hospital, Mbarara, Uganda. Ann Global Health 83(1):18-19

30. Murray CJ, Lopez AD (1997) Global mortality, disability, and the contribution of risk factors: global Burden of Disease Study. Lancet 349(9063):1436-1442

31. Saxton AT, Poenaru D, Ozgediz D et al (2016) Economic analysis of children's surgical care in low- and middle-income countries: a systematic review and analysis. PLoS ONE 11(10): 0165480

32. Goodman LF, St-Louis E, Yousef Y et al (2018) The global initiative for children's surgery: optimal resources for improving care. Eur J Pediatr Surg Off J Austrian Assoc Pediatr Surg [et al] = Zeitschrift fur Kinderchirurgie 28(1):51-59

33. Adeyemo WL, James O, Butali A (2016) Cleft lip and palate: parental experiences of stigma, discrimination, and social/structural inequalities. Ann Maxillofac Surg 6(2):195-203

34. Magee WP Jr, Vander Burg R, Hatcher KW (2010) Cleft lip and palate as a cost-effective health care treatment in the developing world. World J Surg 34(3):420-427. https://doi.org/10.1007/ s00268-009-0333-7

35. Farmer D, Sitkin NA, Lofberg KP , Ozgediz D. Surgical Interventions for Congenital Anomalies. Chapter 8. DCP-3

36. Wang H, Naghavi M, Allen C, Barber RM, Bhutta ZA, Carter A, Casey DC, Charlson FJ, Chen AZ, Coates MM, Coggeshall M
(2016) Global, regional, and national life expectancy, all-cause mortality, and cause-specific mortality for 249 causes of death, 1980-2015: a systematic analysis for the Global Burden of Disease Study 2015. Lancet 388(10053):1459-1544

37. Gosselin R, Ozgediz D, Poenaru D (2013) A square peg in a round hole? Challenges with DALY-based "burden of disease" calculations in surgery and a call for alternative metrics. World $\mathrm{J}$ Surg 37(11):2507-2511. https://doi.org/10.1007/s00268-0132182-7

38. Murray C, Lopez A (1996) The global burden of disease: a comprehensive assessment of mortality and disability from diseases, injuries and risk factors in 1990 and projected to 2020. Harvard University Press, Cambridge

39. Salomon JA, Vos T, Hogan DR et al (2012) Common values in assessing health outcomes from disease and injury: disability weights measurement study for the Global Burden of Disease Study 2010. Lancet 380(9859):2129-2143

40. World Health Organization (2015) The global burden of disease: 2004 update. http://www.who.int/healthinfo/global_burden_dis ease/2004_report_update/en/. Accessed 11 Aug 2015

41. Kuznik A, Lamorde M, Hermans S et al (2012) Evaluating the cost-effectiveness of combination antiretroviral therapy for the prevention of mother-to-child transmission of HIV in Uganda. Bull World Health Organ 90(8):595-603

42. Yap A, Cheung M, Muzira A et al (2019) Best buy in public health or luxury expense?: the cost-effectiveness of a pediatric operating room in Uganda from the societal perspective. Ann Surg

43. Yap A, Muzira A, Cheung M et al (2018) A cost-effectiveness analysis of a pediatric operating room in Uganda. Surgery 164(5):953-959

44. Grabski D, Ameh E, Ozgediz D, Oldham K, Abantanga FA, Abdel-malak M, Abdulraheem N, Ade-Ajayi N, Ismail A, Ademuyiwa A, Ahmed E (2019) Optimal resources for children's surgical care: executive summary. World J Surg 43(4):978-980. https://doi.org/10.1007/s00268-018-04888-7

45. Global Initiative for Children's Surgery (2019) A model of global collaboration to advance the surgical care of children. World $\mathrm{J}$ Surg 43(6):1416-1425. https://doi.org/10.1007/s00268-01804887-8

46. Butler MW, Ozgediz D, Poenaru D et al (2015) The global paediatric surgery network: a model of subspecialty collaboration within global surgery. World J Surg 39(2):335-342. https://doi. org/10.1007/s00268-014-2843-1

47. Ologunde R, Maruthappu M, Shanmugarajah K, Shalhoub J (2014) Surgical care in low and middle-income countries: burden and barriers. Int J Surg 12(8):858-863

48. Bearden A, Fuller AT, Butler EK et al (2018) Rural and urban differences in treatment status among children with surgical conditions in Uganda. PLoS ONE 13(11):e0205132

49. Smith ER, van de Water BJ, Martin A et al (2018) Availability of post-hospital services supporting community reintegration for children with identified surgical need in Uganda. BMC Health Serv Res 18(1):727

50. Fuller AT, Haglund MM, Lim S et al (2016) Pediatric neurosurgical outcomes following a neurosurgery health system intervention at Mulago Hospital in Uganda. World Neurosurg 95:309-314

51. Smith ER, Vissoci JRN, Rocha TAH et al (2017) Geospatial analysis of unmet pediatric surgical need in Uganda. J Pediatr Surg 52:1691-1698 
52. Concepcion TL, Smith ER, Mohamed M et al (2019) Provision of surgical care for children across Somaliland: challenges and policy guidance. World J Surg 43:2934-2944. https://doi.org/10. 1007/s00268-019-05079-8

53. New World Bank GDP and Poverty Estimates for Somaliland. http://www.worldbank.org/en/news/press-release/2014/01/29/newworld-bank-gdp-and-poverty-estimates-for-somaliland. Accessed 25 May 2019

54. Smith ER, Concepcion TL, Mohamed M et al (2019) The contribution of pediatric surgery to poverty trajectories in Somaliland. PLoS ONE 14(7):e0219974

55. Poenaru D, Pemberton J, Cameron BH (2015) The burden of waiting: dALYs accrued from delayed access to pediatric surgery in Kenya and Canada. J Pediatr Surg 50(5):765-770
56. Wilson J, Hodges A (2012) Cleft lip and palate surgery carried out by one team in Uganda: Where have all the palates gone? Cleft Palate-Craniofacial J Off Publ Am Cleft Palate-Craniofacial Assoc 49(3):299-304

57. Smith ER, Concepcion TL, Niemeier KJ, Ademuyiwa AO (2019) Is global pediatric surgery a good investment? World J Surg 43(6):1450-1455. https://doi.org/10.1007/s00268-018-4867-4

Publisher's Note Springer Nature remains neutral with regard to jurisdictional claims in published maps and institutional affiliations. 